\title{
The Analysis for Energy Consumption of Marine Air Conditioning System Based on VAV and VWV
}

\author{
Sai Feng $X U^{1, *}$, Xing Lin YANG ${ }^{1}$, and Zou Ying $L E^{1}$ \\ ${ }^{1}$ School of Energy and Power, Jiangsu University of Science and Technology, Zhenjiang 212003, China
}

\begin{abstract}
For ocean-going vessels sailing in different areas on the sea, the change of external environment factors will cause frequent changes in load, traditional ship air-conditioning system is usually designed with a fixed cooling capacity, this design method causes serious waste of resources. A new type of sea-based air conditioning system is proposed in this paper, which uses the sea-based source heat pump system, combined with variable air volume, variable water technology. The multifunctional cabins' dynamic loads for a ship navigating in a typical Eurasian route were calculated based on Simulink. The model can predict changes in full voyage load. Based on the simulation model, the effects of variable air volume and variable water volume on the energy consumption of the air-conditioning system are analyzed. The results show that: When the VAV is coupled with the VWV, the energy saving rate is $23.2 \%$. Therefore, the application of variable air volume and variable water technology to marine air conditioning systems can achieve economical and energy saving advantages.
\end{abstract}

\section{Introduction}

More than $85 \%$ of ship air conditioners operate at partial load. The load is usually $60 \%$ to $80 \%$ of rated load[1]. However, the selection of a ship's equipment is usually based on the maximum load of the equipment. During actual operation, this situation results in waste energy and causes inefficient operation of the equipment, leading to the equipment not achieving its basic requirements for cabin comfort $[2,3]$.

Zhou Hongyu [4] applied variable air volume and variable water volume systems to a large commercial airconditioning system. The results show that the average energy-saving rate of chilled water pump can reach $47 \%$ when the variable air volume and variable water volume are coupled. This shows that VAV, VWV regulation not only allows the vessel to maintain the thermal comfort of the ship's cabin while sailing, but also saves energy [5]. Land and ship air conditioning systems have something similar. However, in the whole sea area, the load is more complicated to Research due to the change of the external environment and seawater temperature, and the research on the energy consumption of air conditioners based on VAV and VWV is lacking. Therefore, this paper conducts in-depth research and analysis on this issue.

\section{Design of ship air conditioning and cabin}

\subsection{Design of the seawater source heat pump air} conditioning system based on VAV and VWV
Conventional ship air conditioning system uses air as the cold [6]. The seawater source heat pump air conditioning system uses sea water as a cold. When the ship is in a different area, the temperature of the air varies greatly, but the temperature of the seawater is relatively stable.

Conventional ship air conditioner uses constant air volume (CAV) and constant water volume (CWV) systems. The variable air volume (VAV) and the variable water volume (VWV) air conditioning system can adapt the change of the cabin load by adjusting the volume of air supply and the flow of the chilled water pump. The reduction of air volume means the reduction of energy consumption and the improvement of energy efficiency.

Route from Asia to Europe through the Mediterranean Sea spans large area which can better be used as research path, therefore, this paper chose three typical shipping areas along this route for load calculation, the ship navigation is divided into Malacca Strait of Kuala Lumpur, Jaffna of Indian Ocean and the Gulf of Aden Obok.

The distribution of the cabin and the main parameters of the superstructure of a ship are as shown in Table1.

Table.1 Main parameters of multifunctional cabins

\begin{tabular}{|c|c|c|}
\hline Cabin name & $\begin{array}{c}\text { Size (length* } \\
\text { width } * \text { height }) \\
(m \cdot m \cdot m)\end{array}$ & crew \\
\hline 101Restaurant & $6 \times 6 \times 2.1$ & 10 \\
\hline 102Kitchen & $4.5 \times 6 \times 2.1$ & 1 \\
\hline 103Restaurant & $6 \times 6 \times 2.1$ & 10 \\
\hline 104meeting room & $6 \times 6 \times 2.1$ & 10 \\
\hline 105Office & $4.5 \times 6 \times 2.1$ & 5 \\
\hline 106meeting room & $6 \times 6 \times 2.1$ & 10 \\
\hline
\end{tabular}




\begin{tabular}{|c|c|c|}
\hline 201 skipper & $4.5 \times 4 \times 2.1$ & 1 \\
\hline 202 crew & $4.5 \times 4 \times 2.1$ & 2 \\
\hline 203 crew & $4.5 \times 4 \times 2.1$ & 2 \\
\hline 204 Captain's Office & $4.5 \times 4 \times 2.1$ & 4 \\
\hline 205 crew & $4.5 \times 4 \times 2.1$ & 2 \\
\hline 206 crew & $4.5 \times 4 \times 2.1$ & 2 \\
\hline 301 bridge & $12 \times 9 \times 2.1$ & 5 \\
\hline
\end{tabular}

According to the relevant ship design standards, when the air conditioning system is cooling, the designed drybulb temperature of indoor air in each cabin is $27^{\circ} \mathrm{C}$, and the relative humidity is $50 \%$.

\section{Mathematical model}

\subsection{The mathematical model of cabin load}

According to the formula of heat and humidity load in airconditioning room[7]:

$$
\frac{d t_{r}}{d t}=\frac{Q_{i n}+Q_{e x}}{v_{r} \rho_{a} C_{P}}+\frac{\rho_{a} V\left(h_{o}-h_{i}\right)}{v_{r} \rho_{a} C_{P}}
$$

Including: $Q_{\lambda}$ is the energy for entering the room per unit time, $k J ; Q_{0}$ is the energy that flows out of the room in unit time, $k J ; Q_{i n}$ is the cooling load caused by the internal heat source, $Q_{e x}$ is the amount of heat that is brought into the room; the volume of the room; $v_{r}$ is the amount of fresh outdoor air; $m^{3} ; V$ is the amount of fresh outdoor air; $m^{3} / h ; h_{o}$ is the value of the outside air, $\mathrm{kJ} / \mathrm{kg} ; \boldsymbol{h}_{i}$ the value of the air inside the cabin; $\mathrm{kJ} / \mathrm{kg}$.

\subsection{Compressor model}

Compressor indicated power:

$$
P_{t h}=P_{s} \cdot V \cdot \frac{k}{k-1} \cdot\left[\left(P_{d} / P_{s}\right)^{\frac{k-1}{k}}-1\right]
$$

Including: $P_{d}, P_{s}$ represents the compressor exhaust, the suction pressure, $\mathrm{Pa} ; \mathrm{k}$ is the thermal insulation.

\subsection{Fan and pump model}

The fan and the water pump are very similar in power and operation characteristics, but used in different places., the model is only used in the case of a fan. This model is also suitable for water pumps [8] According to the law of similarity, there is a relationship between the flow rate, pressure head and speed of a fixed fan.

$$
\left(\frac{n_{d}}{n}\right)^{2} S Q^{2}=f\left(\frac{n_{d}}{n} Q\right)
$$

Fan shaft power:

$$
W_{m}=\frac{P \cdot q_{v}}{\eta_{m} \eta_{n}}
$$

Including: $W_{m}$ is the Shaft power of the fan, $k W ; \eta_{m}$ is the total pressure efficiency of the fan, $\eta_{n}$ is the fan efficiency, $P$ is the total wind pressure of the fan, $q_{v}$ is the air volume of the fan, $m^{3} / s$.

\section{Analysis of Ship Air Conditioning System}

\subsection{Analysis of the energy consumption of the Marine VAV and VWV Air Conditioning System}

Marine air conditioning system mainly includes chiller, water system and wind system. The water system includes chilled water pump and cooling water pump $[9,10]$.Analysis of table 2 shows that the VAV+VWV air conditioning system, the compressors energy consumption accounted for the proportion of total energy consumption of the air conditioning system remaining above $50 \%$, the average proportion was $53.8 \%$, the average proportion of fans accounted for $29.2 \%$, the cooling water pump and chilled water pump accounted for $8.8 \%, 8.16 \%$, respectively. From the above, energy consumption of compressor is the most important factor leading to the change of total energy consumption of ship cabins, followed by fans, chilled water pumps are also a factor affects the total energy consumption, while the proportion of cooling water pumps is small, which has

\begin{tabular}{|c|c|c|c|}
\hline & \multicolumn{3}{|c|}{ Kuala Lumpur } \\
\hline & $\max$ & $\min$ & average \\
\hline compressor & 54.47 & 40.00 & 53.40 \\
\hline Fan & 34.72 & 28.23 & 29.13 \\
\hline $\begin{array}{c}\text { Cooling water } \\
\text { pump }\end{array}$ & 11.95 & 7.85 & 9.29 \\
\hline \multirow[t]{3}{*}{$\begin{array}{l}\text { Chilled water } \\
\text { pumps }\end{array}$} & 13.32 & 7.87 & 8.19 \\
\hline & \multicolumn{3}{|c|}{ Jaffna } \\
\hline & $\max$ & $\min$ & average \\
\hline compressor & 55.13 & 52.10 & 53.77 \\
\hline Fan & 29.83 & 28.19 & 29.09 \\
\hline $\begin{array}{l}\text { Cooling water } \\
\text { pump }\end{array}$ & 11.85 & 6.72 & 9.02 \\
\hline \multirow[t]{3}{*}{$\begin{array}{l}\text { Chilled water } \\
\text { pumps }\end{array}$} & 8.31 & 7.86 & 8.11 \\
\hline & \multicolumn{3}{|c|}{ Obock } \\
\hline & $\max$ & $\min$ & $\begin{array}{c}\text { avera } \\
\text { ge }\end{array}$ \\
\hline compressor & 55.55 & 52.19 & 54.28 \\
\hline Fan & 30.06 & 28.24 & 29.37 \\
\hline $\begin{array}{l}\text { Cooling water } \\
\text { pump }\end{array}$ & 11.71 & 6.02 & 8.17 \\
\hline $\begin{array}{l}\text { Chilled water } \\
\text { pumps }\end{array}$ & 8.38 & 7.87 & 8.18 \\
\hline
\end{tabular}
little effect on total energy consumption.

Table.2 The percentage of energy consumed in total energy consumption under the VAV+VWV 


\subsection{Changes in total Energy Consumption of VAV and VWV Air Conditioning Systems at Different Time of the Whole Day}

Figures 1 and 2 show that the changes in the total energy consumption of the VAV system and the VAV+VWV system at different times of the whole day. During the period of 10:00 19:00, the energy consumption of the marine air conditioning system increased first and then decreased, and the total energy consumption reached the peak at 17:00. In Obock, which is typical the area waters, the total energy consumption of the maximum variation, diurnal energy consumption maximum difference was $11.3^{\circ} \mathrm{C}$ and the average difference was $8.2^{\circ} \mathrm{C}$. As the variation curves of ship air conditioning system show that energy consumption is different with time within the same area, routes within the area also has different energy consumption. The estimation of traditional ship air conditioning system load is obviously larger, so the total energy consumption is also higher than the energy consumption when using VAV+VWV technology. Therefore, by adjusting the air volume and water volume to adapt to the change of cabin load, economic and energy saving can be achieved.

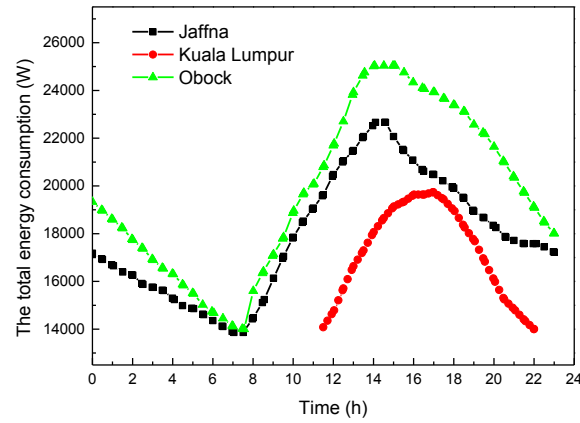

Fig. 1 The energy consumption of each equipment under the VAV at different time of the whole day Lumpur

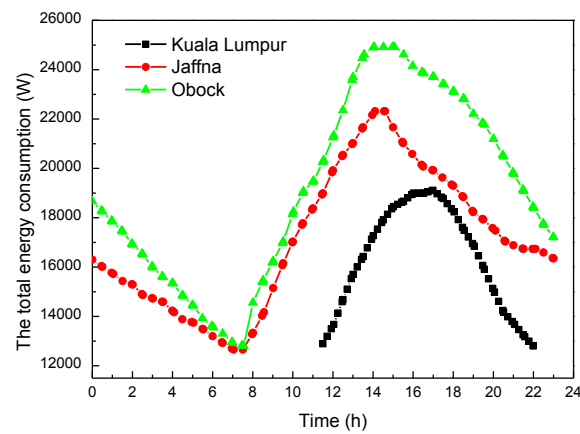

Fig. 2 The energy consumption of each equipment under the VAV+VWV at different time of the whole day

\subsection{Calculation of energy consumption of traditional ship air-conditioning system}

The heat load Q of a ship's air conditioner is mainly composed of five parts: incoming heat $Q_{1}$, human body $Q_{2}$ heat, lighting heat $Q_{3}$, fresh air heat $Q_{4}$, and heat penetration of the air duct. $Q_{5}$

$$
Q_{1}=h A_{1}\left(t_{o}-t_{n}\right)+h A_{1} \Delta t_{r}+h_{g} A_{g}\left(t_{o}-t_{n}\right)_{5}+G_{s} A_{s}
$$

Including: $A_{1}$ is the area after deduction of the glass window, $m^{2} ; \boldsymbol{t}_{o}, \boldsymbol{t}_{n}$ is the design temperature outside or inside of the cabin, ${ }^{\circ} \mathrm{C} ; \Delta t_{r}$ is the solar radiation temperature rise on the sun surface; $h_{g}$ is the coefficient of heat transfer on the solar window, $W /\left(\mathrm{m}^{2} \cdot K\right)$.

$$
Q_{4}=\rho_{a} V\left(h_{o}-h_{i}\right)
$$

The vessel is closed tightly therefore penetration load is not considered, the heat of the body and the heat dissipation are only rough estimates. The formula above is used to calculate the available items and the total load as shown in Table 3.

Table. 3 cabin load steady state calculation results

\begin{tabular}{|c|c|c|c|c|}
\hline$Q_{1} / W$ & $Q_{2} / W$ & $Q_{3} / W$ & $Q_{4} / W$ & $Q / W$ \\
\hline 9542 & 7767 & 5781 & 12712 & 35802 \\
\hline
\end{tabular}

According to the calculation example of this paper, the total energy consumption of the traditional ship air conditioning system under the refrigeration condition of a certain navigation area is shown in table 4 .

Table.4 the total energy consumption of the traditional ship air conditioning system under the cooling condition

\begin{tabular}{|c|c|c|c|c|c|}
\hline$W_{i}(W)$ & $W_{m}(W)$ & $W_{s}(W)$ & $W_{q}(W)$ & $W(W)$ & $Q(W)$ \\
\hline 12268 & 6563 & 2200 & 1500 & 22531 & 32646.3 \\
\hline
\end{tabular}

\subsection{Comparison between VAV, VWV ship air conditioning system and traditional ship air conditioning system}

The energy saving rate calculation formula is:

$$
\varphi=\frac{\Delta E}{E}
$$

Including: $\Delta E$ is the energy that can be saved, $k J$, $E$ is the energy consumed before the conversion of the air-conditioning system, $k J$.

Including: In view of energy consumption analysis, the following three comparative analyses are proposed: 1 . $\mathrm{CAV}+\mathrm{CWV} ; 2$. VAV $+\mathrm{CWV} ; 3$. VAV+VWV;

From Table 5, it can be seen that the energy saving rates when using VAV technology and VAV + VWV in the Kuala Lumpur are $23.24 \%, 27.04 \%$, respectively. Therefore, it is better to use conversion technology for ship air conditioning than traditional ship air conditioning system. 
Table.5 The economical analyses of ship air conditioning system

\begin{tabular}{|c|c|c|}
\hline & VAV & VAV+VWV \\
\hline $\begin{array}{c}\text { Kuala } \\
\text { Lumpur }\end{array}$ & $23.24 \%$ & $27.04 \%$ \\
\hline Jaffna & $20.58 \%$ & $24.18 \%$ \\
\hline Obock & $12.43 \%$ & $15.24 \%$ \\
\hline
\end{tabular}

\section{Conclusion}

In this paper, the model of ship air conditioning system was established. The cabin load of certain areas was calculated by cabin model and then the energy consumption of water chiller, fan, chilled water pump and cooling water pump were calculated; by analyzing the relationship between energy consumption of VAV, VWV and $\mathrm{CAV}, \mathrm{CWV}$, the following conclusions can be drawn:

1) In the ship air-conditioning system, the largest energy consumption area is the refrigeration unit, which accounts for $52.4 \%$ of the total energy consumption, whiles the fan accounts for $28.9 \%$. The energy consumption of the cooling water pump and the frozen water pump account for $7.4 \%, 11.3 \%$, respectively.

2) The energy saving rate is about $23.1 \%$ when the combination of the air-changing and the water-changing were used. According to the energy saving calculations, the ship air-conditioning system which uses frequency conversion technology is obviously superior to the conventional ship air conditioning system. Therefore, the application of the air-changing and the water-changing technology in ship air conditioning system can achieve economic and energy saving advantages, and this also has important significance in engineering application.

\section{References}

1. Cheng Hua, Zhao Zhongchao, Shi Ce. The analysis for Dynamic load of ocean-going ship air conditioning system [J]. Journal of Jiangsu University of Science and Technology(Natural Science), 2015, 29(1):64-69.

2. Li Weiguang, Li Anbang, Xu Xinhua, et al. Discussion on the Value of Heat Transfer Coefficient of Complex Ship Surrounding Wall[J]. Chinese Ship Research, 2014(2):78-83.

3. Mu Qinghao. Research on Energy Saving of Variable Frequency Regulation of Ship Air Conditioning System[D]. Dalian Maritime University, 2016.

4. Zhou Hongyu, Chen Xiaojian, Chen Yuhu. Central air-conditioning energy-saving control strategy for changing water volume and variable air volume $[\mathrm{J}]$. Control Engineering. 2011, 18(3):

5. Zeng Qinyang. Research on Energy Consumption Distribution and Energy Efficiency Evaluation of "Yanyu" Ship[D]. Dalian Maritime University, 2012.

6. Li Jun. A new type of marine air conditioning system and its characteristics analysis [D]. Jiangsu University of Science and Technology, 2016.
7. Han Baoqi. Principles and Applications of Refrigeration and Air Conditioning [M]. Mechanical Industry Press, 2002.

8. Yu Longqing. Variable flow analysis of air conditioning cooling water system[J]. Energy Conservation, 2014(11):53-55.

9. Zhao Zongzhou. Energy consumption modeling and optimization simulation of VAV air conditioning system [D]. Qingdao Technological University, 2016.

10. Wang Shenglong, Li Guoping. Analysis of variable flow energy saving for centrifugal chillers and air conditioning systems [J]. Refrigeration and Air Conditioning, 2016, 16(4): 61-64. 